\title{
Investigation of Ultrasonic Flowmeter Error in Distorted Flow Using Two-peak Salami Functions
}

\author{
Fedir Matiko, Vitalii Roman ${ }^{*}$, Halyna Matiko, Dmytro Yalinskyi \\ Lviv Polytechnic National University, 12 Stepan Bandera St., Lviv, 79013, Ukraine
}

Received: November 29, 2021. Revised: December 14, 2021. Accepted: December 20, 2021.

(c) 2021 The Authors. Published by Lviv Polytechnic National University.

\begin{abstract}
Results of investigating the additional error of ultrasonic flowmeters caused by the distortion of the flow are presented in the article. The location coordinates of acoustic paths were calculated for their number from 1 to 6 according to the different numerical integrating methods: Gauss (Gauss-Legendre, Gauss-Jacobi), Chebyshev (equidistant location of acoustic paths), Westinghouse method, method of OWICS (Optimal Weighted Integration for Circular Sections). This made it possible to realize the flowrate equation for multi-path ultrasonic flowmeters and to determine their additional error for different location of the acoustic paths. The average flow velocity along each path is calculated based on the flow velocity profile in the pipe cross section. Four two-peak Salami functions of velocity are used to calculate the velocity profile of the distorted flow caused by typical local resistances. According to the research results the recommendations were developed for choosing the number of the acoustic paths of the ultrasonic flowmeters and for using the methods for determining the location coordinates of the acoustic paths.
\end{abstract}

Keywords: ultrasonic flowmeter; additional error; distorted flow; velocity profile; Salami function.

\section{Introduction}

Due to their advantages ultrasonic flowmeters (USMs) have been widely used to measure flowrate and volume of fluids [1]-[2]. Nevertheless, USMs have their own disadvantages such as high sensitivity to deviation of flow parameters during operation from the conditions of their calibration, particularly, the distortion of the flow (velocity profile). A significant additional error of the USM may occur in a distorted flow [1]-[2].

The flowrate measurement error of distorted flows can be reduced in several ways [1]:

1) by installing straight pipe section of sufficient length upstream the USM;

2) by using special flow conditioner upstream the USM;

3) by increasing the number of acoustic paths (APs) and improving their location schemes.

Increasing the number of chordal AP (which lie in a plane far from the center of the pipe) can significantly improve the accuracy of measurement of the flowrate of distorted flows. However, the design of such USM is more complicated and it is more expensive. Therefore, the question arises about the choice of minimum number of chordal AP that are sufficient to achieve the given accuracy of flowrate measurement.

Such experimental studies require a special installation as well as USM with the ability to change the number of APs and their location schemes, which significantly increases the research cost. Therefore, it is necessary to investigate the effect of the APs number on the USM measuring error by simulating using computer technologies. It

\footnotetext{
*Corresponding author. Email address: vitalii.i.roman@lpnu.ua
}

This paper should be cited as: F. Matiko, V. Roman, H. Matiko, D. Yalinskyi. Investigation of ultrasonic flowmeter error in distorted flow using two-peak Salami functions. Energy Engineering and Control Systems, 2021, Vol. 7, No. 2, pp. 144 - 151. https://doi.org/10.23939/jeecs2021.02.144 
is much cheaper than experiments. The simulation allows selecting effective location schemes of APs, reducing the list of schemes for experimental study, as well as reducing the duration of the experiment.

\section{Analysis of recent publications and research works on the problem}

Using the Salami functions of velocity for solving the problems of USMs is considered in many research works [3]-[12]. In particular, the Salami functions were used in these works to investigate the flowrate measurement errors and USMs characteristics depending on the number, type and location scheme of APs.

In the article [3] the authors investigated the USM with the chordal location scheme of APs by using one peak Salami functions of the velocity as the models of distorted flow. The main influence factors on the flow measurement error of USM under the conditions of distorted flows were highlighted in the article. It was found for chordal USM that four APs are sufficient to meet the requirements of the standard [1] to the additional error of flowrate measurement caused by the distorted flow (this error should not exceed $\pm 0.3 \%$ ).

The purpose of this article is to investigate the chordal USM error in distorted flow using two-peak Salami functions P5, P7, P10 and P16 as models of the distorted flow [4], [5]. These functions describe the flow velocity profile at the typical fittings outlet such as two $90^{\circ}$ bends in one plane of the U-configuration, two $90^{\circ}$ bends in one plane of the S-configuration, two $90^{\circ}$ bends in different planes [4]-[5].

\section{Theoretical material and research}

The volume flowrate measured by chordal multipath USM is calculated by the equation [11]:

$$
q_{U S M}=\pi R^{2} \sum_{i=1}^{N}\left(\frac{2 \sqrt{R^{2}-x(i)^{2}}}{\pi R} w(i) u_{h}(i)\right)
$$

where $q_{U S M}$ is the volume flowrate; $R$ is the internal radius of the USM section; $x(i)$ is the location coordinate (see Fig.1); $w(i)$ is the weight coefficient of $i$-th chordal AP; $u_{h}(i)$ is the average flow velocity along the $i$-th chordal AP; $N$ is the number of chordal AP of USM. To implement equation (1) it is necessary to determine the parameters $x(i)$ and $w(i)$ for each USM and the average flow velocity $u_{h}(i)$ along each chordal AP.

According to [1] the weight coefficients $w(i)$ can be constant or variable. In this paper the authors investigated the flowrate measurement error of chordal USM with the location of APs according to the following methods [5], [8]:

1) a numerical integrating method (NIM) (Gauss-Legendre, Gauss-Jacobi methods for $\alpha=\beta=0$ );

2) a numerical integrating method by Chebyshev (equidistant location of APs);

3) a numerical integrating method by Gauss-Jacobi (Gauss-Chebyshev second order). This method is also called the Westinghouse method [9];

4) an improved method of OWICS (Gauss-Jacobi for $\alpha=\beta=0.6$ ) [11].

A detailed technique for calculating $x(i)$ and $w(i)$ based on classical and advanced numerical methods is described in $[11,13]$. The authors have implemented the method [13] and calculated the values $x(i)$ and $w(i)$ using the above methods for the number of APs $N=2 \ldots 6$. The calculated values of $x(i)$ and $w(i)$ are presented in Table 1.

The Table 1 allows realizing the equation (1) for UMSs with the number of paths from 2 to 6.

The value of the average flow velocity $u_{h}(i)$ along each chordal AP can be determined based on the flow velocity profile in the cross section of the pipeline [8]. We propose to apply empirically obtained functions of the velocity distribution of the distorted flow in the cross section of the pipeline (Salami functions of the velocity) in order to construct the flow velocity profile. These functions are obtained by the method described in [4]. A set of two-peak Salami functions of the velocity is developed by this technique. They describe the kinematic structure of the distorted flow downstream the fittings (mostly $90^{\circ}$ bends and their combinations) [4].

Functions of velocity are received by professor L.A. Salami based on the following theoretical considerations [4]:

1) Any velocity profile of the distorted flow through the pipeline of cylindrical form is presented as a sum of two components - the main (symmetric $u_{s y m}$ ) and polynomial (asymmetric $u_{a s y m}$ ): $u_{S A L}=u_{s y m}+u_{\text {asym }}$. 
2) The symmetric component of the velocity $u_{s y m}$ in the turbulent flow regime is determined by the simplified power law distribution: $u_{s y m}=(1-r(j))^{1 / n}$, where $n$ is the power exponent, that describes the flow velocity profile and depends on the Reynolds number Re; $r(j)$ is the radial coordinate of the $j$-th point of the cross section of the pipeline.

3) Various expressions are used to describe the polynomial velocity component $u_{\text {asym }}$. In this work we used the expression: $u_{\text {asym }}=m r(1-r(j))^{1 / n} f(\theta(j))$, where $m$ is a profile form factor; $f$ is a certain model function; $\theta(j)$ is the angular coordinate of the $j$-th point of the cross section of the pipeline.

4) Each Salami function is the dependence of the relative velocity $u / u_{\max }$ on the relative radius $r / r_{\max }\left(r_{\max }=R\right)$ and the angle coordinate $\theta$. Therefore it enables the calculating the velocity values at an each point of the cross section of the pipeline, particularly along the AP.

Table 1. Location coordinates $x(i)$ and the weights $w(i)$ of AP.

\begin{tabular}{|c|l|l|l|l|l|l|l|c|}
\hline \multirow{2}{*}{$N$} & \multicolumn{2}{|c|}{ Chebyshev [14] } & \multicolumn{2}{c|}{ Gauss [14] } & \multicolumn{2}{c|}{ Gauss-Jacobi [14] } & \multicolumn{2}{c|}{ OWICS [10] } \\
\cline { 2 - 9 } & \multicolumn{1}{|c|}{$x(i)$} & $w(i)$ & $x(i)$ & $w(i)$ & $x(i)$ & $w(i)$ & $x(i)$ & $w(i)$ \\
\hline \hline 2 & \pm 0.5774 & 1 & \pm 0.5774 & 1 & \pm 0.5 & 0.9069 & \pm 0.4880 & 0.8908 \\
\hline \multirow{3}{*}{3} & \pm 0.7071 & $2 / 3$ & \pm 0.7746 & 0.5555 & \pm 0.7071 & 0.5554 & \pm 0.6956 & 0.5537 \\
\cline { 2 - 9 } & 0 & $2 / 3$ & 0 & 0.8888 & 0 & 0.7854 & 0 & 0.7687 \\
\hline \multirow{3}{*}{4} & \pm 0.7947 & 0.5 & \pm 0.8610 & 0.3479 & \pm 0.8090 & 0.3693 & \pm 0.7996 & 0.3719 \\
\cline { 2 - 9 } & \pm 0.1876 & 0.5 & \pm 0.3400 & 0.6521 & \pm 0.3090 & 0.5976 & \pm 0.3038 & 0.5882 \\
\hline \multirow{4}{*}{5} & \pm 0.8325 & $2 / 5$ & \pm 0.9062 & 0.2369 & \pm 0.8660 & 0.2618 & \pm 0.8585 & 0.2654 \\
\cline { 2 - 9 } & \pm 0.3745 & $2 / 5$ & \pm 0.5385 & 0.4786 & \pm 0.5 & 0.4535 & \pm 0.4933 & 0.4489 \\
\cline { 2 - 9 } & 0 & $2 / 5$ & 0 & 0.5688 & 0 & 0.5236 & 0 & 0.5158 \\
\hline \multirow{4}{*}{6} & \pm 0.8662 & $2 / 6$ & \pm 0.9325 & 0.1713 & \pm 0.9010 & 0.1947 & \pm 0.8949 & 0.1984 \\
\cline { 2 - 8 } & \pm 0.4225 & $2 / 6$ & \pm 0.6610 & 0.3608 & \pm 0.6235 & 0.3509 & \pm 0.6167 & 0.3489 \\
\cline { 2 - 8 } & \pm 0.2666 & $2 / 6$ & \pm 0.2386 & 0.4679 & \pm 0.2225 & 0.4375 & \pm 0.2197 & 0.4321 \\
\hline
\end{tabular}
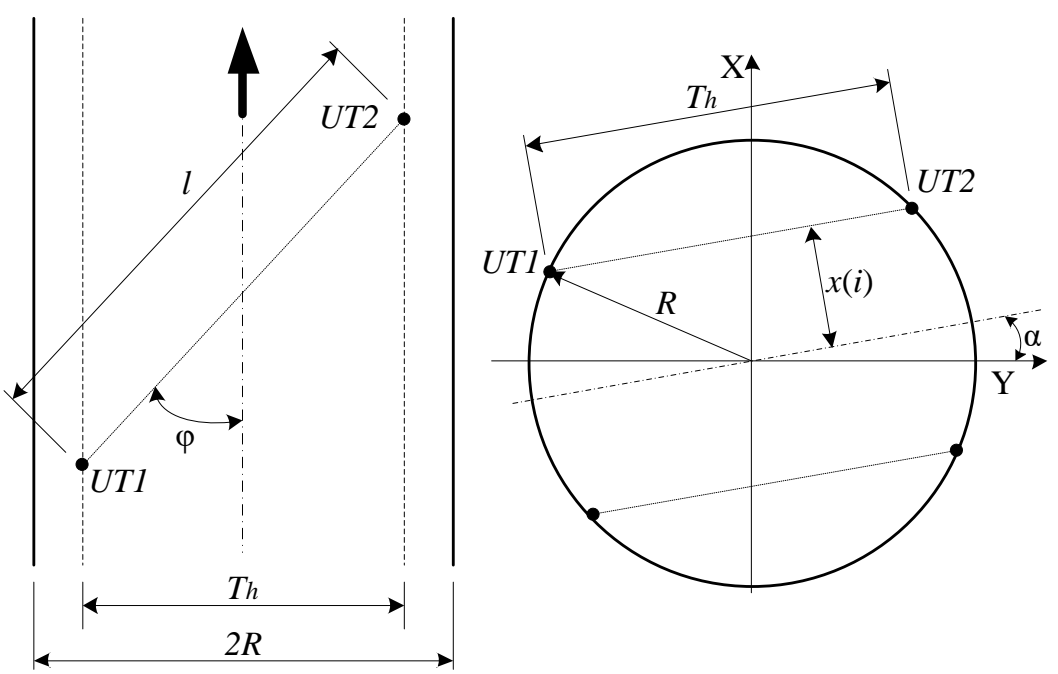

Fig.1. Simplified location scheme of chordal APs of USM: UT - ultrasonic transducer.

We can calculate the average flow velocity along the $i$-th chordal APs of USM (see Fig.1) by the following formula [8]:

$$
u_{h}(i)=\frac{1}{T_{h}(i)}\left[\begin{array}{c}
\int_{0}^{\sqrt{R^{2}-x(i)^{2}}} u_{S A L}\left(\sqrt{x(i)^{2}+l^{2}}, \alpha+\operatorname{arctg} \frac{l}{x(i)}\right) d l+ \\
+\int_{0}^{\sqrt{R^{2}-x(i)^{2}}} u_{S A L}\left(\sqrt{x(i)^{2}+l^{2}}, \alpha-\operatorname{arctg} \frac{l}{x(i)}\right) d l
\end{array}\right],
$$


where $u_{S A L}$ is one of the Salami functions of the velocity; $T_{h}(i)=2 \sqrt{R^{2}-x(i)^{2}}$ is the width of the plane of the $i$-th chordal AP; $l$ is the length of the chordal AP of USM; $\alpha$ is the rotation angle of the plane of passing of chordal AP relative to the horizontal plane (see Fig.1). In this paper, the angle $\alpha=0^{\circ}$, since this angle corresponds to the typical location of the AP of USM [1], [6].

The results of the calculation of the flow rate by the equation (1) on the basis of the average velocity values for each AP obtained by the formula (2) will differ from the flow rate calculated by direct integration of the velocity profile of the undistorted flow. This is due to the error of integrating the velocity profile with a limited number of points (flow rates for each AP). In the manufacture of USM, this effect is eliminated by finding a calibration curve the dependence of the calibration coefficient on the flow rate (or Reynolds number) [3]. The authors propose to determine the calibration coefficient $k_{\text {cal }}$ by the formula:

$$
k_{c a l}=\frac{q}{q_{U S M}}=\frac{2 \pi \cdot \int_{0}^{1}\left(r \cdot u_{s y m}\right) d r}{\pi R^{2} \sum_{i=1}^{N}\left(\frac{2 \sqrt{R^{2}-x(i)^{2}}}{\pi R} w(i) u_{h}(i)\right)},
$$

where $q$ is the exact value of the volume flowrate obtained by direct integration of the velocity profile of the undistorted flow; $u_{s y m}$ is a symmetric, undistorted component of the Salami function, which is identical to the power law of the velocity distribution [4].

Taking into account the value $k_{c a l}$ and formula (2) the final flowrate equation of USM (1) takes the form:

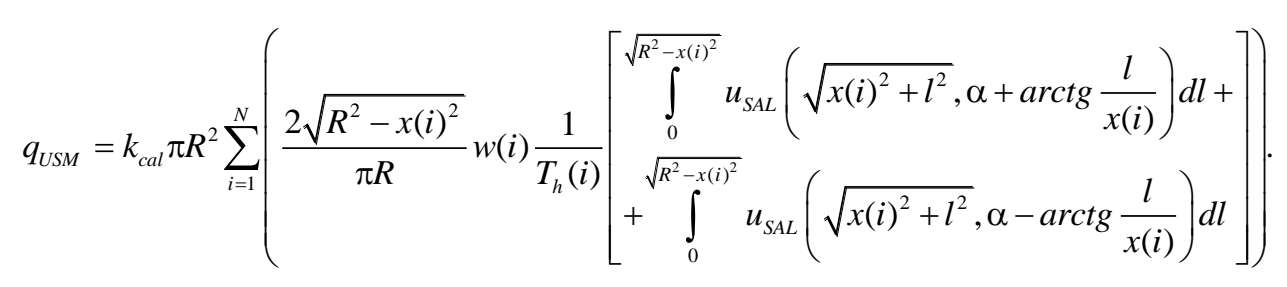

Thus, calibration coefficient determined for undistorted flow is used in the equation (4). It is obvious that using this equation to calculate the flowrate of a distorted flow will result in additional error, which actually occurs as a result of distortion of the flow velocity. The relative additional flowrate measuring error should be determined by the formula:

$$
\delta_{A}=\frac{q_{U S M}-q_{S A L}}{q_{S A L}} \cdot 100
$$

where $q_{S A L}$ is the exact value of the volume flowrate of the distorted flow, for which the velocity profile is described by the Salami function.

The flowrate $q_{S A L}$ is calculated by the formula:

$$
q_{S A L}=\int_{0}^{2 \pi}\left(\int_{0}^{1} r \cdot u_{S A L}(r, \theta) d r\right) d \theta .
$$

Four two-peak Salami functions are used in this article to investigate the error $\delta_{A}$ [4], [5]. The analytical expressions for these functions and the dimensionless values of flowrate $q_{S A L}$ are given in Table 2.

The additional flowrate measurement error caused by the distortion of the flow is investigated for multipath USMs by the following technique:

1) Flowrate equation for the USM is obtained for a fixed number $N$ by substituting $x(i)$ and $w(i)$ into equations (1) and (2) from Table 1. 
2) The calibration coefficient kcal is calculated by the formula (3) for the conditions of undistorted flow. The below factors should be taken into account:

- power exponent $n$ for the Salami function [3]-[5], which characterizes the profile of the flow velocity, depends on the Re and determines the type of function (for two-peak Salami functions P5, P7 and P10 $n=9$, and for Salami functions P16 $n=7$ [4], [5]);

- number of APs USM $N$;

- values of $x(i)$ and $w(i)$ (see Table 1$)$.

Table 2. Two-peak Salami functions [5].

\begin{tabular}{|c|c|c|}
\hline Function & Analytical expression functions & $q_{S A L}$ \\
\hline \hline $\mathrm{P} 05$ & $u=(1-r)^{\frac{1}{9}}+0.6813 r(1-r)^{\frac{1}{9}} e^{-0.1 \theta}(\sin \theta)^{2}$ & 3.1130 \\
\hline $\mathrm{P} 07$ & $u=(1-r)^{\frac{1}{9}}+\frac{1}{\pi^{2}}(1-r)^{\frac{1}{4}} \theta\left(1-(\cos \theta)^{2}\right)$ & 2.8974 \\
\hline $\mathrm{P} 10$ & $u=(1-r)^{\frac{1}{9}}+\frac{2}{\pi^{3}} r(1-r)^{\frac{1}{4}}(2 \pi-\theta)(\sin \theta)^{2}$ & 2.9925 \\
\hline $\mathrm{P} 16$ & $u=(1-r)^{\frac{1}{7}}+e^{0.1 \theta} r(1-r)^{\frac{1}{9}} e^{-0.2 \theta}(\sin \theta)^{2}$ & 2.8237 \\
\hline $\mathrm{P} 05$ & $u=(1-r)^{\frac{1}{9}}+0.6813 r(1-r)^{\frac{1}{9}} e^{-0.1 \theta}(\sin \theta)^{2}$ & 3.1130 \\
\hline
\end{tabular}

3) The value of the average flowrate along each of $i$-th AP was calculated by formula (2) for chosen Salami function (see Table 2).

4) The flowrate measured by USM was calculated by formula (4) according to the flow conditions described by two-peak Salami function.

5) The relative flowrate measurement error was calculated by formula (5) for USM with different number and location schemes of APs $(x(i)$ and $w(i)$ are calculated by different methods).

6) A conclusion was made about the required minimum number of APs based on the dependence of the additional flowrate measurement error on the number $N$. Particularly, taking into account the requirement of ISO 17089-1 [1, pp. 5.9.3.2] to the maximum additional flowrate measurement error caused by distortion of the flow it was found

$$
\left|\delta_{A(N)}^{\max }-\delta_{A(N+1)}^{\max }\right|<0,3 \%
$$

The results of calculating $k_{\text {cal }}$ for different input data are given in Table 3.

Table 3. Values of the calibration coefficient $k_{\text {cal }}$.

\begin{tabular}{|c|l|c|c|c|c|c|c|}
\hline \multirow{2}{*}{$n$} & \multirow{2}{*}{ Numerical integrating methods } & \multicolumn{6}{|c|}{$k_{\text {cal }}$} \\
\cline { 3 - 8 } & & $N=1$ & $N=2$ & $N=3$ & $N=4$ & $N=5$ & $N=6$ \\
\hline \hline \multirow{4}{*}{7} & Chebyshev & 0.9333 & 0.9752 & 0.9813 & 0.9908 & 0.9932 & 0.9970 \\
\cline { 2 - 8 } & Gauss & 0.9333 & 0.9752 & 0.9879 & 0.9970 & 0.9973 & 0.9991 \\
\cline { 2 - 8 } & Gauss-Jacobi & 0.9333 & 0.9928 & 0.9942 & 0.9988 & 0.9985 & 0.9996 \\
\cline { 2 - 8 } & OWICS & 0.9333 & 0.9910 & 0.9970 & 1.0001 & 0.9992 & 1.0000 \\
\hline \multirow{4}{*}{9} & Chebyshev & 0.9474 & 0.9716 & 0.9799 & 0.9902 & 0.9927 & 0.9964 \\
\cline { 2 - 8 } & Gauss & 0.9474 & 09716 & 0.9877 & 0.9963 & 0.9972 & 0.9989 \\
\cline { 2 - 8 } & Gauss-Jacobi & 0.9474 & 0.9938 & 0.9953 & 0.9989 & 0.9988 & 0.9997 \\
\cline { 2 - 8 } & OWICS & 0.9474 & 1.0016 & 0.9984 & 1.0003 & 0.9996 & 1.0001 \\
\hline
\end{tabular}

The results of the studying of additional flowrate measurement error $\delta_{A}$ are shown in Fig.2. 

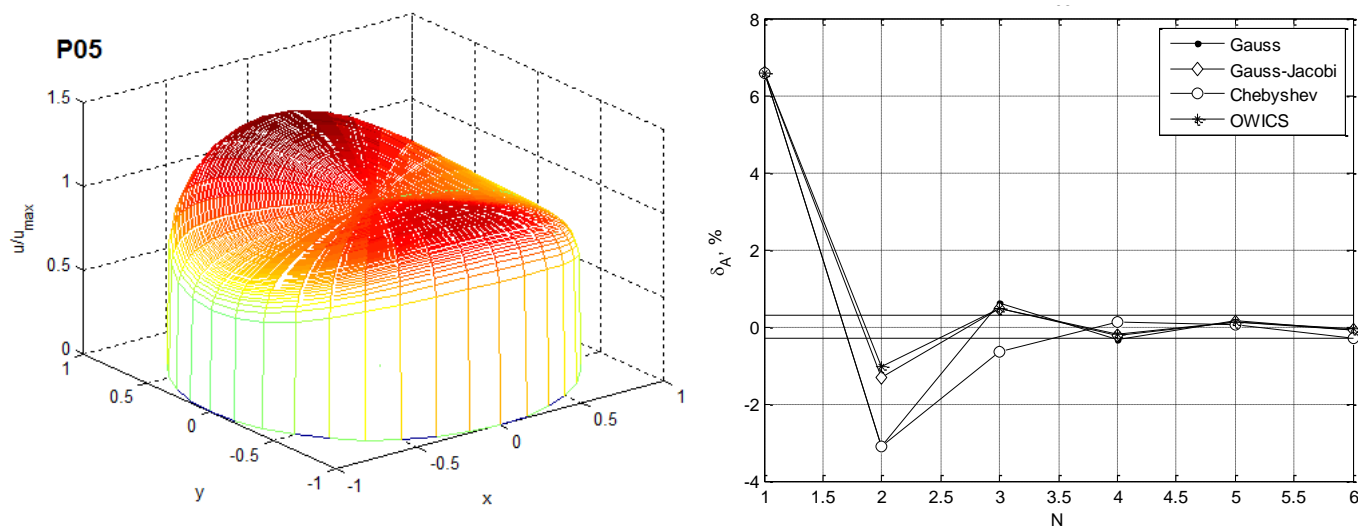

a)
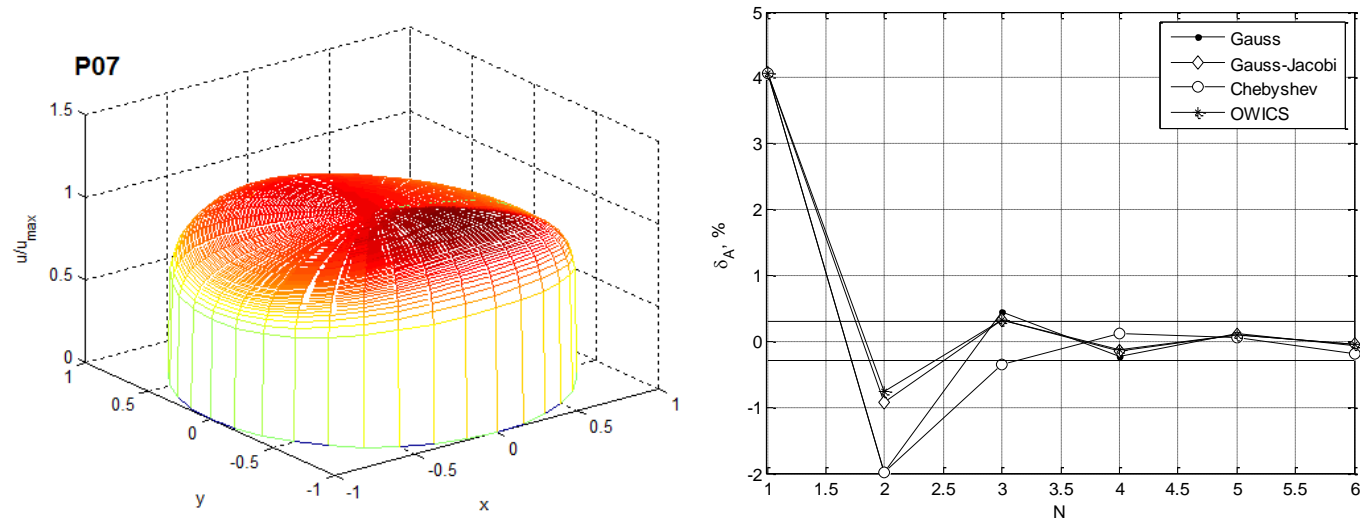

b)
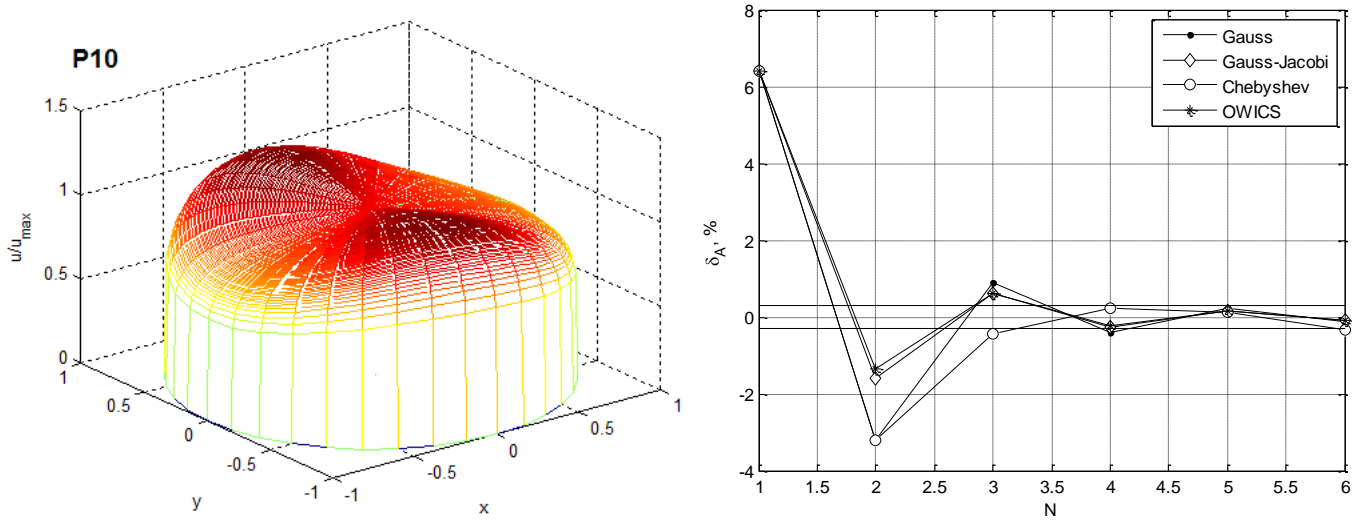

c)
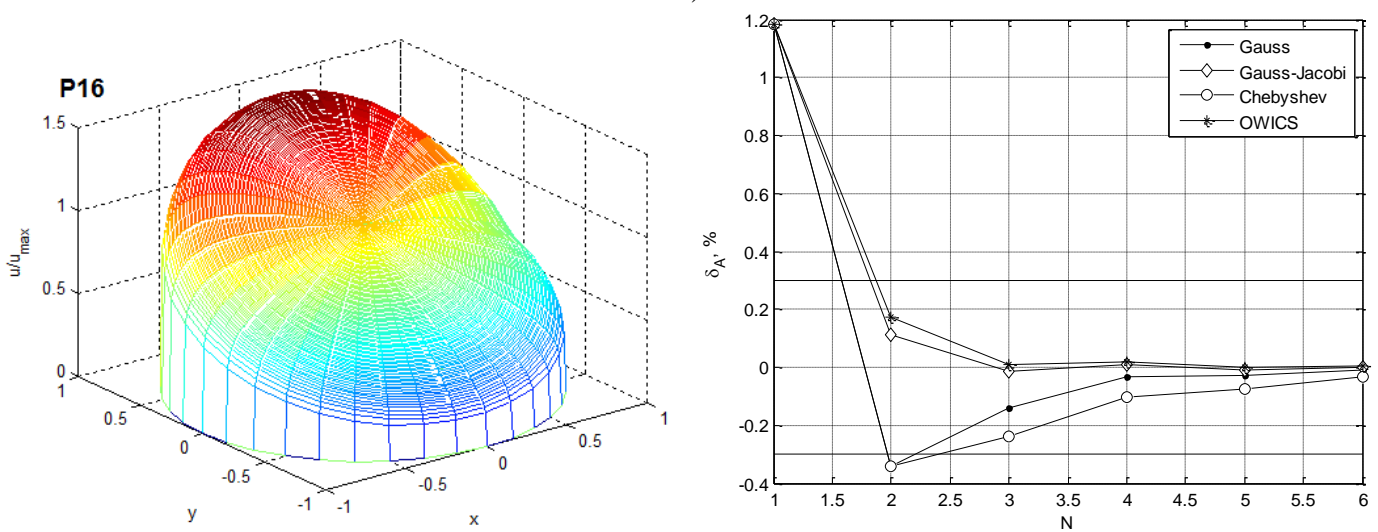

d)

Fig.2. Profiles of 3D functions and the corresponding dependences of additional flowrate measurement error on the number of APs $N$ for the functions P05 (a), P07 (b), P10 (c) and P16 (d). 


\section{Conclusion}

In the article we investigated ultrasonic flowmeter error in distorted flow using two-peak Salami functions.

The main factors that affect the additional flowrate measurement error $\delta_{A}$ are as follows: the type of flow distortion, the number of APs and their location scheme. Increasing the number of APs and the correct choice of their location scheme can reduce the effect of flow distortion.

For three considered two-peak Salami functions only the USM with $N \geq 4$ will satisfy the requirement (7) to the additional flowrate measurement error $\delta_{A}$. For such USM the method for determining the location coordinates and the weight coefficients of the APs slightly affects the flowrate measurement result under the conditions of distorted flow. Increasing of the APs number to more than 4 is inadvisable, since the value of the flowrate measurement error does not decrease much $( \pm 0.1 \%)$ compared to the error at $N=4$.

The method for determining the $x(i)$ and $w(i)$ significantly affects the flowrate measurement error $\delta_{A}$ at $N<4$. In this case none of the numerical integrating method can satisfy the condition (7). For the one-peak Salami functions the condition (7) is satisfied using the method Gauss-Jacobi and OWICS. This conclusion confirms the known practice result, when the increase in the number of peaks of the velocity profile (complicating the fitting type) increases the flowrate measurement error of the USM.

The obtained research results make it possible to improve the design of the USMs and to reduce the additional flowrate measurement error under the conditions of the distorted flow.

\section{References}

[1] ISO 17089-1: Measurement of fluid flow in closed conduits - Ultrasonic meters for gas. Part 1: Meters for custody transfer and allocation measurement, Geneva, 2010.

[2] Lunde P., Froysa K.-E. and Vestrheim M. (2000) GERG Project on ultrasonic gas flow meters, Phase II : technical monograph TM 11, Brussels.

[3] Roman V.I. and Matiko F.D. (2017) Investigation of ultrasonic flowmeter error in conditions of distortion of flow structure using one peak functions Salami. Metrology and devices, 3, 36-43. (in Ukrainian)

[4] Salami L.A. (1984) Application of a computer to asymmetric flow measurement in circular pipes. Trans. Inst. Meas. Control, 6, 197-206. https://doi.org/10.1177/014233128400600403

[5] Moore P.L., Brown G.J. and Stimpson B.P. (2000) Ultrasonic transit-time flowmeters modelled with theoretical velocity profiles: Methodology. Meas. Sci. Technol., 11, 1802-1811. https://doi.org/10.1088/0957-0233/11/12/321

[6] Dorozhovets M.M., Semenystyi A.V. and Stadnyk B.I. (2004) Theoretical analysis of the spatial distribution of the fluid velocity using functions Salami for multi-path ultrasonic flowmeter. Bulletin of LPNU : Automation, measurement and control, 500, 131-134. (in Ukrainian)

[7] Korobko I.V. and Volynska Ya.V. (2013) Assessment of fluid flow asymmetry in the measurement of flow rate and volume. Bulletin of

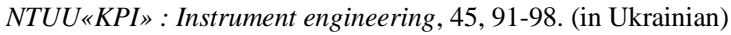

[8] Masloboev Ju.P., Ruchkin S.V., Rychagov M.N. and Tereshhenko S.A. (2002) Characterization of perturbed streams based on ultrasonic measurements using a set of basic Salami functions. Proceedings of the Nizhny Novgorod acoustic scientific session, 1, 388-390. (in Russian)

[9] Zanker K.J. (1999) The effects of Reynolds number, wall roughness, and profile asymmetry on single- and multi-path ultrasonic meters. Proceedings of XVII International North Sea Flow Measurement Workshop, Oslo, 25-28 October 1999, 117-129.

[10] Dandan Zheng, Dan Zhao and Jianqiang Mei (2015) Improved numerical integration method for flowrate of ultrasonic flowmeter based on Gauss quadrature for non-ideal flow fields. Flow Measurement and Instrumentation, 41, 28-35. https://doi.org/10.1016/j.flowmeasinst.2014.10.005

[11] Tresch T., Gruber P. and Staubli T. (2006) Comparison of integration methods for multipath acoustic discharge measurements. Proceedings of VI International Conference on "IGHEM", Portland Oregon, 30 July - 1 August 2006.

[12] Duffell C.J., Brown G.J., Barton N.A. and Stimpson B.P. (2003) Using optimization algorithms and CFD to improve performance of ultrasonic flowmeters. Proceedings of II International South East Asia Hydrocarbon Flow Measurement Workshop, Kuala Lumpur, 25-28 March 2003

[13] Roman V.I. and Matiko F.D. (2014) Definition of weighting coefficients of acoustic channels for ultrasonic flowmeters. Metrology and devices, 3, 11-20. (in Ukrainian) 


\title{
Дослідження похибки ультразвукового витратоміра за умов спотвореної структури потоку із застосуванням двоядерних функцій Саламі
}

\author{
Федір Матіко, Віталій Роман, Галина Матіко, Дмитро Ялінський \\ Національний університет «Львівська політехніка», вул. Степана Бандери, 12, Львів, 79013, Украӥна
}

\section{Анотація}

В статті представлено результати досліджень додаткової похибки ультразвукових витратомірів (УЗВ), зумовленої спотворенням профілю швидкості потоку. Координати розташування хордових акустичних каналів (АК) обчислено для кількості АК від 1 до 6 за допомогою різних числових методів інтегрування: Гауса (Гауса-Лежандра, Гауса-Якобі), Чебишева (рівновіддалене розміщення АК), методу Westinghouse, методу OWICS (Optimal Weighted Integration for Circular Sections). Це дало можливість реалізувати рівняння витрати багатоканального УЗВ та оцінити додаткову похибку УЗВ за умови різного розміщення АК. Значення середньої швидкості потоку вздовж кожного АК визначене розрахунковим шляхом на основі профілю швидкості потоку в поперечному перерізі ВТ. Для обчислення профілю швидкості спотвореного потоку, сформованого типовими місцевими опорами, застосовано чотири двоядерні функції швидкості Саламі. За результатами дослідження додаткової похибки УЗВ в умовах спотвореного потоку розроблено рекомендації щодо вибору кількості акустичних каналів УЗВ та застосування методів визначення координат розташування акустичних каналів.

Ключові слова: ультразвуковий витратомір; додаткова похибка; спотворений потік; профіль швидкостей; функція Саламі. 